\title{
County-level association of unemployment to mortality in the coterminous United States: a Bayesian spatiotemporal modeling approach
}

\author{
Insang Song \\ Department of Geography, University of Oregon \\ 160 Condon Hall, 1251 University of Oregon, Eugene, OR 97403-1251, United States \\ E-mail: isong@uoregon.edu
}

\begin{abstract}
This study spatiotemporally examines an association between unemployment and mortality. Hypothesizing the spatiotemporally heterogeneous association, we employ the Integrated Nested Laplace Approximation (INLA)-based random slope model with the spatiotemporal interaction under the control of common covariates. The model design aims to investigate the spatiotemporally transforming relationship between unemployment rates and mortality rates. The causes for all, self-harm, and mental disorders in 3,108 coterminous counties in the United States for 2001-2014, which includes two economic recessions, are considered. The results show the sporadic spatial effect and the cause-specific change of spatiotemporal interactions during the study period. The spatiotemporal patterns did not only have the same magnitude but also show the same direction of shift for causes of death. The spatiotemporal changes of the associations of one-year lagged unemployment rates are summarized as follows: (1) Dakotas and the west Appalachian counties have highly positive association in recent years; (2) the geographical shifts in high association regions were various for each cause of death: the dividing cluster for all-cause, the southerly moving cluster for the self-harm and interpersonal violence, and intensifying clusters in central and west Appalachian for the mental and substanceuse disorders mortality; (3) the associations become weaker during the Great Recession period. Those patterns may be attributed to regional contexts, such as devoid of healthcare facilities and psychological deprivation. Even though there are possible mediating factors indicated by the substantial degree of residuals in some regions, our approach illustrates that the association of unemployment and mortality is spatiotemporally different across regions. It also suggests the spatiotemporal approach is effective in investigating the relationship between unemployment and mortality.
\end{abstract}

Keywords: Unemployment, Mortality, Integrated Nested Laplace Approximation (INLA), Spatiotemporal interaction, Spatial inequality 


\section{Introduction}

The association between unemployment and human mortality has been extensively studied in community health literature. Since Pierce questioned a plausible relationship between business cycles and suicide rates (Pierce 1967), the following study by Kasl mentioned the cautions on studies to examine such relationship (Kasl 1979). Studies on examining the association began from the simple association between the time series of national mortality rates and unemployment index (Brenner 1971) then focused on longitudinal follow-up or cohort design (Moser, Fox, and Jones 1984; Gerdtham and Johannesson 2003; Voss et al. 2004) and individual level studies (Martikainen and Valkonen 1996; Mäki and Martikainen 2012), which were non-spatial at large. For specific causes of deaths, suicide has been examined to have the association between mortality in New Zealand (Blakely, Collings, and Atkinson 2003), in Sweden by the twin registry (Voss et al. 2004), in Canada by the cohort design (Mustard et al. 2013) and in Western European countries (Laanani et al. 2015).. . Mental disorders were reported to be attributable to the increase in unemployment rates (De Vogli, Vieno, and Lenzi 2014) and liver cancer (Singh, Siahpush, and Altekruse 2013). A meta-analysis study reported that the risk of death among unemployed persons had been $63 \%$ higher than employed persons (Roelfs et al. 2011).

Much fewer studies, however, have explicitly taken the spatial dimension into account and explored whether the difference in the association varies over space. Compared to a body of literature on examining the national scale and individual-level association (Catalano et al. 2011; Tapia Granados et al. 2014). Some country-scale comparative studies have shown the different degree of response of unemployment to mortality as comparing the labor policy or skill level of labor by countries, they, however, still accepted country as a unit of analysis without introducing sub-national level analysis or spatial modeling approach (McLeod et al. 2012; Norström and Grönqvist 2015). There has also been an array of studies investigating the community-level association between unemployment and mortality. Following the pioneering study of Waitzman and Smith showing that the higher mortality risk in poverty areas (Waitzman and Smith 1998), a few studies employed the comparative method such as van Lenthe et al. which examined that neighborhoods in the highest quartile had increased mortality hazards compared to the lowest quartile as their statistical significance varied in six countries (van Lenthe et al. 2005). Halliday reported that poor local labor market conditions had the association with higher mortality risk for working-aged men, but no significant association for the 
elderly and women (Halliday 2014). However, very few studies explicitly introduced a spatial component in the analysis, let alone a spatiotemporal one.

In this study, we examine two questions: (1) does the association between the unemployment rates and mortality rates in the US spatially vary at the county level? We hypothesize that the association varies over space; (2) what was the spatiotemporal impact of unemployment rates on mortality rates in two economic recessions during the 2001-2014 in the US? We hypothesized the effect of the recession on the mortality rates would be spatially differential. This question spatially — and spatiotemporally_reiterates the continued debate on the impact of economic recession proxied by unemployment rates on human mortality. In sum, the questions reexamine Roelfs et al., which concluded that statistically, the mortality does not depend on the unemployment by analyzing individual-level studies with meta-regression models (Roelfs et al. 2015). We aim to find whether the national-scale result remains at the local level within the spatiotemporal setting. We also re-examine the assertion that the recession is 'beneficial' to the mortality (i.e., recession decreases mortality rate) (Ruhm 2000; Neumayer 2004; Miller et al. 2009; Ariizumi and Schirle 2012), as the study period includes two recessions in 2001 and 2008 (The National Bureau of Economic Research 2020).

\section{Methods}

Data

\section{Mortality data}

We use the county-level mortality rates data from the Institute for Health Metrics and Evaluation (IHME) (Institute for Health Metrics and Evaluation 2016). It released 25 causespecific mortality rates at the county level in 1980-2014. The data in 2001-2014 is extracted from the original IHME data. There are 21 categories that were reclassified based on the international classification of diseases $9^{\text {th }}$ and $10^{\text {th }}$ revision (Dwyer-Lindgren et al. 2016). We selected three of them for the analysis which are often referred to in previous review articles: allcause, self-harm and interpersonal violence, and mental and substance-use disorders (Milner, Page, and LaMontagne 2013, 2014; Probst et al. 2014; Frasquilho et al. 2016). The mortality data is at the county level, a geography hierarchy that remains constant during our study period (2001-2014). This boundary consistency avoids the misalignment problem (Gryparis et al. 2009). 


\section{Covariate data}

The covariate data for fixed effects are obtained referring to the previous studies employing regional scales or spatial approach: county-level median household income, educational attainment, population distribution for age and race groups (Jia, Moriarty, and Kanarek 2009; van den Berg et al. 2017; Moortel et al. 2018; Ballester et al. 2019). The unemployment rates data is obtained from the Local Area Unemployment data, which recorded monthly unemployment rates in all counties in the United States since 1976 (U.S. Bureau of Labor Statistics 2019). We use the yearly average unemployment rate (marked as month 13 in the data) for the main analysis. Covariates such as county-level median household income, educational attainment, population distribution for age and race groups were obtained from the IPUMS National Historical Geographical Information System (Ruggles 2014; Manson et al. 2019). Additionally, the median household income data from 2000 and 2010 censuses are adjusted to the value of 2000 using the Bureau of Labor Statistics Consumer Price Index Inflation Calculator (The Bureau of Labor Statistics 2020). For spatial analysis, the county boundary in 2014 is obtained from the Census Bureau (United States Census Bureau 2015).

As the data has some missing values due to low base population or confidentiality issues, the missing values are imputed with the global median. According to Harrell, the estimation for the parameters is not contaminated even if one employs a simpler imputation method when the missing rate is lower than 3\% (Harrell 2015). As our dataset has less than $1 \%$ of the missing rate, we decided to impute missing data by the median imputation method.

\section{Statistical procedure}

The model fit was done following the integrated nested Laplace approximation (INLA) method. The INLA method assumes the latent Gaussian distributions to estimate marginal posteriors, which is effective when the number of hyperparameters is small (Gelman 2014). Our spatiotemporal regression model setting is effective to investigate the spatial variability on the impact of the fluctuation of unemployment rates. Spatiotemporal model can be described as follows:

$$
\begin{aligned}
& y_{i t}=\beta_{0}+\beta_{i t 1} x_{i t 1}+\sum_{k=2}^{9} \beta_{k} x_{i t k}+u_{i}+v_{i}+\gamma_{t}+\delta_{i t} \\
& \beta_{i t 1}=b_{i t 1,0}+b_{i t 1,1}, \\
& b_{i t 1,0} \sim \mathcal{N}\left(0, \nu_{0}^{2}\right)
\end{aligned}
$$


The cause-specific mortality rate for county $i$ and year $t, y_{i t}$, are described as the formula (1). The formula is the expansion of the formula in Blangiardo and Cameletti $(2015,240)$, by including a spatiotemporal random slope for the unemployment variable, say, $x_{i t 1}$, UELAG1 in Table 1. The unemployment rate variable is modelled to have a random slope; Thus, the fixed part of $b_{i t 1,1}$ is separated from the random noise, $b_{i t 1,0}$. Each of them is spatiotemporally structured such that non-noise parts $b_{i t 1,1}$ were modelled to have spatiotemporally autoregressive coefficients. The fixed effect of other covariates is controlled by $\beta_{k} x_{i t k}$, which is defined for the $k$-th $(k=2, \ldots, 9)$ variable for every single data point.

$u_{i}$ and $v_{i}$ are spatially structured and exchangeable effects for every county, and they are included at once by employing the Besag-York-Mollié model specification (Besag, York, and Mollié 1991). The spatially structured effect is administered by the distribution of near (described as spatially lagged in some literature) spatial entities. $\gamma_{t}$ is the temporal effect incorporating temporally autocorrelated functions by imposing a first-order autoregressive structure referring to the partial autocorrelation function results of the residuals of the model with the spatial component. $\delta_{i t}$ is the spatiotemporal interaction term (Banerjee, Carlin, and Gelfand 2015; Blangiardo and Cameletti 2015), in this case, embedded in the random slope part $b_{i t 1,1}$. As each year's data contain eight variables from two decennial censuses during the study period, we match the covariates of the 2000 Census to 2001-2009 mortality rates and the 2010 Census to 2010-2014 mortality rates. The spatial dependency is modelled with the first-order contiguity (known as Queen's contiguity) that consider adjacent counties sharing a vertex of a certain county as contiguous counties.

The spatiotemporal interaction term is imposed in the random slope term:

$$
\mathbf{R}_{\delta}=\mathbf{R}_{u} \otimes \mathbf{R}_{\gamma}
$$

where $\otimes$ is the Kronecker product, which makes an augmented matrix comprising spatial and temporal dependencies. In this case, we have $\mathbf{R}_{\delta}$ with $3,108 \times 14^{2}$ elements as the spatiotemporal interaction matrix. In plain words, it capture the first-order random walk (denoted as RW(1) now on) temporal structure with $\mathbf{R}_{\gamma}$ and first-order spatial contiguity structures with conditional autoregressive prior (Besag 1974) with $\mathbf{R}_{u}$ at once, thereby borrow the strength of neighboring counties of the one year before (Khana et al. 2018). For the detailed description of computational procedures, we recommend readers refer to the supplementary material 1. 
We take various modeling approaches to find the most decent model, by including or excluding spatial or temporal component to avoid overfitting. Our three modeling approaches are as below:

Model 0: Fixed effect only $\left(\beta_{0}+\sum_{k=1}^{9} \beta_{k} x_{i t k}\right.$; base model $)$

Model 1: temporal component and spatiotemporal interaction $\left(\beta_{0}+\beta_{i t 1} x_{i t 1}+\right.$ $\left.\sum_{k=2}^{9} \beta_{k} x_{i t k}+\gamma_{t}+\delta_{i t}\right)$

1-1. Independently identically distributed (IID) temporal structure in the spatiotemporal interaction

1-2. $\mathrm{RW}(1)$ temporal structure in the spatiotemporal interaction

Model 2: Spatial component and spatiotemporal interaction $\left(\beta_{0}+\beta_{i t 1} x_{i t 1}+\sum_{k=2}^{9} \beta_{k} x_{i t k}+\right.$ $\left.u_{i}+v_{i}+\delta_{i t}\right)$

2-1. IID temporal structure in the spatiotemporal interaction

2-2. RW(1) temporal structure in the spatiotemporal interaction

Model 3: Full model $\left(\beta_{0}+\beta_{i t 1} x_{i t 1}+\sum_{k=2}^{9} \beta_{k} x_{i t k}+u_{i}+v_{i}+\gamma_{t}+\delta_{i t}\right)$

3-1. IID temporal structure in the spatiotemporal interaction

3-2. RW(1) temporal structure in the spatiotemporal interaction

Priors for the hyperparameters in each model are imposed as default distribution of precisions $\log \Gamma(1,0.00005)$. Models are evaluated by the deviation information criterion (DIC, Spiegelhalter et al. 2002) and the widely applicable (also known as Watanabe-Akaike) information criterion (WAIC, Watanabe 2009). All statistical analyses are conducted with R 3.6.1 and R package INLA version 2019.09.03 with the PARDISO solver to handle the large spatiotemporal problem (Rue, Martino, and Chopin 2009; Verbosio et al. 2017; R Core Team 2019). 
Table 1

List of variables

\begin{tabular}{|c|c|c|}
\hline Variable name & Description & Remarks \\
\hline Mortrate & $\begin{array}{l}\text { All-cause, Mental and substance-use, Self-harm and inter- } \\
\text { personal violence mortality (per 100,000 persons) }\end{array}$ & Dependent \\
\hline UELAG1 & The unemployment rate of one year before & Variable of interest \\
\hline MEDINCOME & $\begin{array}{l}\text { Median household income in } 1,000 \text { dollars in the census } \\
\text { year ( } 2000 \text { inflation adjusted) }\end{array}$ & $\begin{array}{l}\text { Economic status } \\
\text { (income) }\end{array}$ \\
\hline PPOVTBELOW & The ratio of the population below the poverty level & $\begin{array}{l}\text { Economic status } \\
\text { (poverty) }\end{array}$ \\
\hline PRENTER & The ratio of renter-occupied housing & $\begin{array}{l}\text { Economic status } \\
\quad \text { (housing) }\end{array}$ \\
\hline PUNIVABOVE & $\begin{array}{l}\text { The ratio of the population with or higher than bachelor's } \\
\text { degree }\end{array}$ & $\begin{array}{l}\text { Population } \\
\text { (education) }\end{array}$ \\
\hline PNONWHITE & The ratio of non-white population & Population (race) \\
\hline PRURAL & The ratio of the rural population (\%) & $\begin{array}{l}\text { Population } \\
\text { (urban-rural) }\end{array}$ \\
\hline PHSINGLE & The ratio of single-person households & $\begin{array}{l}\text { Population } \\
\text { (household) }\end{array}$ \\
\hline PELDER & The ratio of the elderly population ( 65 years old or older) & Population (age) \\
\hline
\end{tabular}

\section{Results}

Descriptive analysis

Table 2 showed that the mortality rates have displayed different temporal patterns by the causes. There were reverse trends in all-cause mortality rates and self-harm and mental disorders mortality rates. The coterminous average all-cause mortality rate has been monotonically decreasing except for the reverse upturn in 2011 , which resulted in $-11.01 \%$ for the study periods. Other causes, however, show the increasing trend; mental and substance-use disorders mortality rates have increased rapidly such that the rate in 2014 increased $76.34 \%$ compared to that of 2001. Self-harm and interpersonal violence mortality rates also increased while its increasing trend was not extreme, as seen in mental and substance-use disorders. There is also to be noted that mortality rates tended to become higher geographical disparity, as observing the standard deviation of the distribution became higher in all causes of death considered in the study. 
The overall distribution of variables showed the long right tail as the medians were lower than the means. Most variables show the symmetric distribution in terms of the difference between the mean, and the median was below $2 \%$. Variables such as median household income, the ratio of non-white population, and the ratio of the rural population had long right tails.

\section{Regression results}

The full model (3-2) gave the lowest model fit measures such as DIC and WAIC in all mortality models considered. As the model with additional terms showed the better fit, two findings should be noted. First, the models regarding the spatial effect (models 2-1 and 2-2) gained more model fit compared to the case of solely regarding the temporal effect (models 11 and 1-2) without the spatial effect (Table 3). The model for self-harm and interpersonal violence was, in particular, significantly benefited by employing the spatial effect considering the difference of DICs or WAICs for the base model and models 2-1 and 2-2. Second, the inclusion of the RW(1) temporal structure in the spatiotemporal interaction term generally improved the model fit. It can be found that the model fit statistics were lower in the spatiotemporal interaction with RW(1) temporal structure denoted as sub-model 2 for all models except for the base model.

Table 5 for the summary statistics of posterior marginals of hyperparameters shows the contributions of each model component to account for the total variance. Considering precision is the inverse of variance, the lower precision indicates the higher contribution to the total variance in each standardized mortality rates of cause of death. The portion was the highest in the spatially unstructured component $\tau_{v}$, which reflected the highly spatially variable nature of mortality rates. Other contributing portions were higher in an order of spatially structured $\left(\tau_{u}\right)$, temporally structured $\left(\tau_{\gamma}\right)$ and spatiotemporal interaction $\left(\tau_{\delta}\right)$ terms. For each cause of death, the relative portion of each component in the mental and substance-use disorders model should be noted. The spatial and temporal component almost equally contributed to the total variance of standardized mortality rates, while the spatiotemporal component contributed more to the total variance in terms of the ratio of spatiotemporal mode precision to the spatial or temporal mode precision than that of other mortality models. Also, the precision of the temporal component in the self-harm and interpersonal violence model was high, which was almost 20 times of the precision of the spatially structured component. This indicated the spatial variability contributed more to the total variability of mortality than its temporal counterpart. The residual 
in each county for each year was illustrated in Figures S10-S12. Residuals tended to be higher in counties with higher absolute random slopes of unemployment rates to mortality rates.

The fixed effect results illustrated the characteristics of each cause of death. Regression coefficients with the same sign for all three models were three out of eight fixed effect variables: the ratio of the population higher than bachelor's degree, the ratio of the population below poverty level, and the ratio of rented housing. The all-cause mortality rates were observed to have a negative association with population characteristics at large, and the educational attainment tended to have the reductive effect on the all-cause mortality rates. The self-harm and interpersonal violence mortality rates showed the solely negative effect in the educational attainment and relatively high association with the age and race composition in each county. Lastly, the mental and substance-use disorders presented the consistent association with income variables which were observed in the negative association with the median household income and the higher positive association with the poverty level and the rented housing (Table 4).

The spatial effects were sporadic in all models (the upper panel in Figures S4-S6). This could be partly attributed to the spatial distribution of the original distribution of mortality rates, which had spatially peaked patterns. The spatial effects in models except for the all-cause mortality model had the long right tail. The higher peaks were observed in the same counties for all models, and it could also be accounted for the high raw mortality rates. The spatial disparity of spatiotemporal interactions significantly decreased during the contraction and recession periods. From 2007, the increasing trend in unemployment rates began, and it was observed that the magnitude of random slopes generally decreased until 2010, the year the unemployment rate peaked.

We highlight three aspects of the results of the random slope coefficients of unemployment rates a year before in the spatiotemporal interaction term: locations of high coefficients on the one hand and the locational shift in high coefficient clusters along the years on the other hand. First, counties in Dakotas and the region in the west Appalachian showed a higher association for three causes of death in recent years. Second, the geographical shifts in high association regions varied for every cause of death. For instance, the all-cause mortality rates showed the divide from the large central cluster to the northern central and the Deep South. The self-harm and interpersonal violence moved southern, while the mental and substance-use disorders contracted toward the center from the coasts. Third and last, the association of unemployment rates to mortality rates was lower during the Great Recession and its extended period (2007-2011) than that of other years in the study period (Figures S4-S6). The probability maps 
showing $p\left(b_{i t 1,1}>0\right)$ illustrate the higher random slope coefficients have higher probabilities (Figures S7-S9). 
Table 2

Summary statistics of variables in 3,108 counties

\begin{tabular}{|c|c|c|c|}
\hline & All-cause & $\begin{array}{l}\text { Self-harm and inter- } \\
\text { personal violence }\end{array}$ & $\begin{array}{c}\text { Mental and } \\
\text { substance-use disorders }\end{array}$ \\
\hline $\begin{array}{c}\text { Mortality rate } \\
\text { (per } 100,000 \text { persons) }\end{array}$ & $912.15(903.22,145.86)^{*}$ & $20.87(20.12,6.39)$ & $10.83(9.54,5.73)$ \\
\hline 2001 & $982.16(972.68,131.35)$ & $19.94(19.32,6.00)$ & $7.44(6.54,3.56)$ \\
\hline 2002 & $979.45(969.99,133.88)$ & $20.11(19.50,6.05)$ & $7.94(7.14,3.82)$ \\
\hline 2003 & $967.85(955.92,135.53)$ & $20.16(19.51,6.09)$ & $8.68(7.79,4.14)$ \\
\hline 2004 & $940.42(928.71,134.71)$ & $20.06(19.39,6.07)$ & $9.20(8.26,4.39)$ \\
\hline 2005 & $937.79(925.99,137.39)$ & $20.52(19.82,6.19)$ & $9.81(8.87,4.70)$ \\
\hline 2006 & $921.39(909.03,137.95)$ & $20.81(20.07,6.30)$ & $10.47(9.45,4.97)$ \\
\hline 2007 & $903.87(892.47,138.02)$ & $20.79(20.08,6.33)$ & $10.93(9.88,5.22)$ \\
\hline 2008 & $896.26(883.94,139.86)$ & $21.00(20.19,6.40)$ & $11.52(10.32,5.57)$ \\
\hline 2009 & $884.43(872.33,140.55)$ & $21.14(20.40,6.47)$ & $11.86(10.67,5.74)$ \\
\hline 2010 & $872.53(860.90,140.73)$ & $21.02(20.28,6.41)$ & $12.17(10.94,6.04)$ \\
\hline 2011 & $873.58(862.07,143.40)$ & $21.43(20.62,6.54)$ & $12.66(11.31,6.34)$ \\
\hline 2012 & $867.84(854.88,145.41)$ & $21.53(20.75,6.62)$ & $12.88(11.50,6.46)$ \\
\hline 2013 & $868.52(855.21,148.33)$ & $21.82(20.97,6.74)$ & $13.12(11.76,6.57)$ \\
\hline 2014 & $874.02(861.02,151.40)$ & $21.86(21.06,6.77)$ & $13.12(11.68,6.78)$ \\
\hline $\begin{array}{c}\text { The unemployment rate in } \\
\text { a year before }(\%)\end{array}$ & \multicolumn{3}{|c|}{$6.57(6.00,2.78)$} \\
\hline $\begin{array}{l}\text { Median household income } \\
\text { (inflation-adjusted dollars } \\
\text { as of 2000) }\end{array}$ & \multicolumn{3}{|c|}{$35563.51(34085.42,9032.27)$} \\
\hline $\begin{array}{l}\text { The ratio of nonwhite pop- } \\
\text { ulation }(\%)\end{array}$ & \multicolumn{3}{|c|}{$15.76(9.42,16.17)$} \\
\hline $\begin{array}{l}\text { The ratio of the population } \\
\text { higher than bachelor's de- } \\
\text { gree }(\%)\end{array}$ & \multicolumn{3}{|c|}{$17.56(15.44,8.28)$} \\
\hline $\begin{array}{l}\text { The ratio of the population } \\
\text { below poverty level }(\%)\end{array}$ & \multicolumn{3}{|c|}{$14.39(13.41,6.31)$} \\
\hline $\begin{array}{l}\text { The ratio of the rural popu- } \\
\text { lation }(\%)\end{array}$ & \multicolumn{3}{|c|}{$49.67(42.87,33.73)$} \\
\hline The ratio of renters $(\%)$ & \multicolumn{3}{|c|}{$26.52(25.22,7.60)$} \\
\hline $\begin{array}{c}\text { The ratio of single-person } \\
\text { households }(\%)\end{array}$ & \multicolumn{3}{|c|}{$25.94(26.03,3.95)$} \\
\hline $\begin{array}{c}\text { The ratio of the elderly } \\
\text { population }(\%)\end{array}$ & \multicolumn{3}{|c|}{$15.22(14.85,4.15)$} \\
\hline
\end{tabular}

*Note: Mean (median, standard deviation) 
Table 3

Model fit statistics

\begin{tabular}{|c|rrrrrr|}
\hline & \multicolumn{2}{|c}{ All-cause } & \multicolumn{2}{c}{$\begin{array}{c}\text { Self-harm and } \\
\text { interpersonal violence }\end{array}$} & \multicolumn{2}{c|}{$\begin{array}{c}\text { Mental and } \\
\text { substance-use disorders }\end{array}$} \\
\cline { 2 - 7 } & \multicolumn{1}{|c}{ DIC } & WAIC & \multicolumn{1}{c}{ DIC } & \multicolumn{1}{c|}{ WAIC } & \multicolumn{1}{c|}{ DIC } & WAIC \\
\hline Model 0 & 90044.74 & 90050.27 & 104309.00 & 104318.90 & 110652.30 & 110660.80 \\
Model 1-1 & 71999.58 & 71118.63 & 93290.09 & 92007.07 & 94900.00 & 93448.55 \\
Model 1-2 & 53624.27 & 50193.76 & 77874.81 & 74381.57 & 80796.59 & 77258.50 \\
Model 2-1 & -12511.16 & -13481.87 & -49233.69 & -49986.50 & 23413.51 & 22076.54 \\
Model 2-2 & -21614.18 & -23135.92 & $\mathbf{- 5 7 1 7 3 . 3 0}$ & $\mathbf{- 5 8 3 7 7 . 6 6}$ & 13465.83 & 11826.21 \\
Model 3-1 & $\mathbf{- 8 6 6 0 5 . 1 8}$ & $\mathbf{- 8 7 3 7 6 . 8 6}$ & $\mathbf{- 5 8 3 4 9 . 8 8}$ & $\mathbf{- 5 8 9 9 0 . 8 0}$ & $\mathbf{- 8 7 7 5 . 6 4}$ & -10233.18 \\
Model 3-2 & $\mathbf{- 1 0 2 2 2 3 . 7 0}$ & $\mathbf{- 1 0 4 1 6 6 . 8 0}$ & $\mathbf{- 6 8 0 0 7 . 9 9}$ & $\mathbf{- 6 9 3 0 2 . 7 2}$ & $\mathbf{- 2 3 8 3 2 . 7 5}$ & $\mathbf{- 2 5 7 9 4 . 8 2}$ \\
\hline
\end{tabular}

Note: The lowest values were highlighted.

Table 4

Regression coefficients of fixed effects of model 3-2

\begin{tabular}{|l|ccc|}
\hline & All-cause & $\begin{array}{c}\text { Self-harm and interper- } \\
\text { sonal violence }\end{array}$ & $\begin{array}{c}\text { Mental and substance- } \\
\text { use disorders }\end{array}$ \\
\hline Intercept & $0.003^{*}$ & 0.002 & -0.021 \\
Median household income & $(-0.011,0.017)^{* *}$ & $(-0.013,0.016)$ & $(-0.034,-0.008)$ \\
(inflation-adjusted dollars as of 2000) & -0.002 & 0.034 & -0.067 \\
Ratio of population below poverty & $(-0.011,0.008)$ & $(0.021,0.048)$ & $(-0.089,-0.045)$ \\
level (\%) & 0.019 & 0.037 & 0.056 \\
Ratio of rented housing (\%) & $(0.013,0.025)$ & $(0.027,0.046)$ & $(0.041,0.072)$ \\
& 0.055 & 0.053 & 0.116 \\
Ratio of population higher than bache- & $(0.045,0.065)$ & $(0.039,0.068)$ & $(0.095,0.137)$ \\
lor's degree (\%) & -0.131 & -0.114 & -0.081 \\
Ratio of nonwhite population (\%) & $(-0.140,-0.122)$ & $(-0.126,-0.101)$ & $(-0.100,-0.063)$ \\
& 0.015 & 0.250 & 0.177 \\
Ratio of rural population $(\%)$ & $(0.000,0.029)$ & $(0.230,0.270)$ & $(0.150,0.205)$ \\
Ratio of single-person households $(\%)$ & 0.019 & 0.001 & -0.036 \\
& $(0.009,0.029)$ & $(-0.013,0.015)$ & $(-0.055,-0.016)$ \\
Ratio of elderly population $(\%)$ & -0.014 & 0.046 & -0.004 \\
& $(-0.023,-0.006)$ & $(0.034,0.058)$ & $(-0.023,0.014)$ \\
& $(-0.035,-0.018)$ & $(0.078,0.103)$ & 0.054 \\
\hline
\end{tabular}

Note: All variables were standardized; *: Mean, **: 95\% credible interval 
Table 5

Summary of model hyperparameters for three causes of death models from the Model 3.2 setting: the summary statistics of posterior marginals and 95\% credible intervals of precisions for each model component

\begin{tabular}{|crrrrr|}
\hline \multicolumn{1}{c}{ Precisions } & Posterior mean & Standard deviation & 2.5\% ile & 97.5\% ile & Posterior mode \\
\hline All-cause model & & & & & \\
$\tau_{u}$ & 6.49 & 0.50 & 5.60 & 7.58 & 6.34 \\
$\tau_{v}$ & 1.62 & 0.14 & 1.34 & 1.90 & 1.64 \\
$\tau_{\gamma}$ & 18.48 & 9.94 & 4.63 & 42.74 & 12.32 \\
$\tau_{\delta}$ & 160.61 & 4.40 & 151.73 & 169.04 & 161.19 \\
\hline Self-harm and interpersonal violence & & & & \\
$\tau_{u}$ & 6.25 & 1.16 & 4.80 & 9.15 & 5.24 \\
$\tau_{v}$ & 1.00 & 0.12 & 0.75 & 1.19 & 1.06 \\
$\tau_{\gamma}$ & 127.76 & 66.92 & 32.74 & 288.96 & 87.13 \\
$\tau_{\delta}$ & 20.50 & 126.97 & 203.86 & 130.89 \\
\hline Mental and substance-use disorders & & & & \\
$\tau_{u}$ & 8.63 & 0.88 & 7.13 & 10.57 & 8.32 \\
$\tau_{v}$ & 1.15 & 0.07 & 1.01 & 1.30 & 1.15 \\
$\tau_{\gamma}$ & 9.91 & 5.80 & 2.27 & 24.31 & 6.09 \\
$\tau_{\delta}$ & 25.74 & 0.68 & 24.43 & 27.12 & 25.69 \\
\hline
\end{tabular}

\section{Discussion}

This study examines the spatiotemporal transformation of the effect of short-term unemployment rates to three mortality rates in 48 coterminous states in the United States at the county level. The temporal impact of unemployment in community level differed by the regions and changed for the study period. Although Roelfs et al. (2015)'s work indicated that few evidences provided the national-level aggregated unemployment is related to the association, our work shows such a conclusion may be spatially inconsistent in a sub-national scale. We would emphasize that the geographical disparity of the effect of short-term unemployment ratesmodelled as a year-lagged unemployment rates - to mortality rates decreased during the increasing phase of unemployment rates. This implies the impact of the increase in unemployment rates lasts longer than the business recession itself. It was demonstrated by the observation that the unemployment rates responded late for the recession period. For instance, we showed the increasing trend in most counties in 2002-2003 for the 2001 recession and the increasing trend in 2009-2011 for the Great Recession (Figures S2-S3). 
The result aligns with the hypothesis and the finding on the 'benefit' of the recession to mortality (Ruhm 2000; Neumayer 2004; Miller et al. 2009; Ariizumi and Schirle 2012), referred to as 'procyclical' in works from economics. As business recessions are not necessarily related to the high unemployment rates, unemployment rates gradually increase after business recessions as more labor force would participate in the labor market in anticipation of the rebound of the business condition (Brenner 2016). Our results give a policy implication that the impact of unemployment to mortality was presumably spatially and temporally different. It indicates that the policy measures should be established in a region-specific way(s) considering the inconsistent and unequal pace of the impact.

Three findings as to the spatiotemporal patterns of the unemployment's effect on allcause, self-harm and interpersonal violence, and mental and substance-use disorders are worth mentioning. First, the low absolute associations of unemployment in most counties in the allcause mortality model can be accounted for the monotonically decreasing all-cause mortality rates. After controlling other factors, the random slopes for unemployment rates might merely explain the rest of mortality rates. Second, High effects of unemployment and suicide and interpersonal violence mortality are observed in the Midwest, in which Native Americans reside and low population density is. This pattern may be mediated by the substantial socio-psychological deprivation (Alcántara and Gone 2007), which may affect youth group in particular (Brockie et al. 2015). Still, there was no consideration about age in this study, so subsequent studies can be guided to examine the various effect of unemployment rate by age groups. Third, the subsisting pattern of high correlation between unemployment and mental and substanceuse mortality in the rural Appalachia can be attributed to the marginalized living condition and distressed economic hardship (Shamblin, Williams, and Bellaw 2012; Moody, Satterwhite, and Bickel 2017) and professional to monitor and take care of ongoing or potential patients (Hendryx 2008). Even though we controlled the typical factors that affect mortality, the high positive residuals in such regions indicate there would be unexplained and intermediating factors that will improve the model (Figure S12).

The hierarchical modeling approach presented the spatiotemporal difference in the impact of unemployment rates to mortality rates. The INLA approach was effective to make an inference on extensive spatiotemporal model with 3,108 counties and 14 years. The approach was highly beneficial to get the result in a modern laptop in an hour, which could take significantly longer when employing a conventional sampling-based Markov Chain Monte Carlo (MCMC)- 
based method. We should mention, however, the selection of the initial values of hyperparameters to start the optimization step in INLA model fitting is crucial to have a sufficient advantage to MCMC as pointed out elsewhere (Carroll et al. 2015). For instance, with 4.0 for all the default values for hyperparameters in INLA, the model sometimes diverged thus we set the initial hyperparameters as all 0.0 instead.

Several limitations should be mentioned. First, we assumed that there is a linear relationship between unemployment and mortality, while individual studies showed that there is a nonlinear relationship between the duration of unemployment and mortality (Garcy and Vågerö 2012; Bonamore, Carmignani, and Colombo 2015). The model developed in this study may be expanded to incorporate the nonlinear term to control the complex effect of unemployment rates. It is closely related to the consideration of long-term unemployment, such as explicitly including multiple lags or multiple-year data in the model (Zheng 2012; Tapia Granados et al. 2014). Second, there might be spatial or spatiotemporal dynamics in other covariates. We examined the random slope in the one-year lagged unemployment rate here, however, there may be another approach — even though it makes the model much more complex — such as adding spatiotemporal interaction random effect terms for variables with high variations. Lastly, here we only considered mortality rates of both sexes and all races in the model. This is largely due to the high missing rate in sex-specific mortality rates and unavailability of sex- and race-specific covariates. The issue can be addressed by introducing spatial estimation and imputation methods (Quick 2019).

Future research can account for the additional factors into the examination of the hypothesis posed in this study from spatial or spatiotemporal perspectives. One can include qualitative factors such as the regime and the policy stance that affect the elasticity of unemployment (Norström and Grönqvist 2015). In terms of the responsive or resilient characteristics of locals toward the economic change, the liberalization of trades and the economic diversity in the composition of industries and businesses in each county would be viable sources of additional covariates (Pierce and Schott 2016; van den Berg et al. 2017; Watson and Deller 2017). Lastly, we can include the variables for the interaction of the environment and the mortality, for instance, industries that are environmentally negative and harmful to human health or the effect of the physical environment to the reduction of mortality risk (Lin et al. 2016; Mueller, Park, and Mowen 2019). Suggestions above would be challenging because these additional factors highly depend on the availability of data on a decently fine spatial scale. 


\section{Conclusion}

We found the spatiotemporally varied association of unemployment to mortality at the county level in the coterminous United States. It contradicts the population-level study results without incorporating the spatial approach at a subnational level. Three patterns that show the spatiotemporal heterogeneity of the associations of unemployment rates to mortality rates are highlighted as follows. First, in recent years, South and North Dakota and the west Appalachian counties show the highly positive association. Second, high association regions geographically shift differently for each cause of death: the dividing cluster for all-cause, the southerly moving cluster for the self-harm and interpersonal violence, and intensifying clusters in central and west Appalachian for the mental and substance-use disorders mortality. Third and last, the associations of unemployment to mortality become weaker during the Great Recession period. Such heterogeneity reflects the regional specific contexts, which should be examined in subsequent studies further. The results also showed the impact of unemployment on mortality decreased during recession periods, especially during the severe economic condition (i.e., the Great Recession). Although this supports the conventional view on the recession might be 'beneficial' for human mortality, further studies that employ an explicit spatial and spatiotemporal approach will be needed to examine the consistency of the result of this study.

\section{References}

Alcántara, C., and J. P. Gone. 2007. Reviewing Suicide in Native American Communities: Situating Risk and Protective Factors within a Transactional-Ecological Framework. Death Studies 31 (5):457-477.

Ariizumi, H., and T. Schirle. 2012. Are recessions really good for your health? Evidence from Canada. Social Science \& Medicine 74 (8):1224-1231.

Ballester, J., J.-M. Robine, F. R. Herrmann, and X. Rodó. 2019. Effect of the Great Recession on regional mortality trends in Europe. Nature Communications 10 (1):1-9.

Banerjee, S., B. P. Carlin, and A. E. Gelfand. 2015. Hierarchical modeling and analysis for spatial data Second edition. Boca Raton: CRC Press.

van den Berg, G. J., U.-G. Gerdtham, S. von Hinke, M. Lindeboom, J. Lissdaniels, J. Sundquist, and K. Sundquist. 2017. Mortality and the business cycle: Evidence from individual and aggregated data. Journal of Health Economics 56:61-70.

Besag, J. 1974. Spatial Interaction and the Statistical Analysis of Lattice Systems. Journal of the Royal Statistical Society. Series B (Methodological) 36 (2):192-236. 
Besag, J., J. York, and A. Mollié. 1991. Bayesian image restoration, with two applications in spatial statistics. Annals of the Institute of Statistical Mathematics 43 (1):1-20.

Blangiardo, M., and M. Cameletti. 2015. Spatial and spatio-temporal Bayesian models with $R-I N L A$. Chichester: John Wiley \& Sons.

Bonamore, G., F. Carmignani, and E. Colombo. 2015. Addressing the unemployment-mortality conundrum: Non-linearity is the answer. Social Science \& Medicine 126:67-72.

Brenner, M. H. 1971. Economic changes and heart disease mortality. American Journal of Public Health 61 (3):606-611.

Brenner, M. H. 2016. The Impact of Unemployment on Heart Disease and Stroke Mortality in European Union Countries. Brussels: European Commission. https://doi.org/10.2767/81253.

Brockie, T. N., G. Dana-Sacco, G. R. Wallen, H. C. Wilcox, and J. C. Campbell. 2015. The Relationship of Adverse Childhood Experiences to PTSD, Depression, Poly-Drug Use and Suicide Attempt in Reservation-Based Native American Adolescents and Young Adults. American Journal of Community Psychology 55 (3-4):411-421.

Carroll, R., A. B. Lawson, C. Faes, R. S. Kirby, M. Aregay, and K. Watjou. 2015. Comparing INLA and OpenBUGS for hierarchical Poisson modeling in disease mapping. Spatial and Spatio-temporal Epidemiology 14-15:45-54.

Catalano, R., S. Goldman-Mellor, K. Saxton, C. Margerison-Zilko, M. Subbaraman, K. LeWinn, and E. Anderson. 2011. The Health Effects of Economic Decline. Annual Review of Public Health 32 (1):431-450.

De Vogli, R., A. Vieno, and M. Lenzi. 2014. Mortality due to mental and behavioral disorders associated with the Great Recession (2008-10) in Italy: a time trend analysis. European Journal of Public Health 24 (3):419-421.

Dwyer-Lindgren, L., A. Bertozzi-Villa, R. W. Stubbs, C. Morozoff, M. J. Kutz, C. Huynh, R. M. Barber, K. A. Shackelford, J. P. Mackenbach, F. J. van Lenthe, A. D. Flaxman, M. Naghavi, A. H. Mokdad, and C. J. L. Murray. 2016. US County-Level Trends in Mortality Rates for Major Causes of Death, 1980-2014. JAMA 316 (22):2385-2401.

Frasquilho, D., M. G. Matos, F. Salonna, D. Guerreiro, C. C. Storti, T. Gaspar, and J. M. Caldas-de-Almeida. 2016. Mental health outcomes in times of economic recession: a systematic literature review. BMC Public Health 16 (1):115.

Garcy, A. M., and D. Vågerö. 2012. The length of unemployment predicts mortality, differently in men and women, and by cause of death: A six year mortality follow-up of the Swedish 1992-1996 recession. Social Science \& Medicine 74 (12):1911-1920.

Gelman, A. 2014. Bayesian data analysis Third edition. Boca Raton: CRC Press.

Gerdtham, U.-G., and M. Johannesson. 2003. A note on the effect of unemployment on mortality. Journal of Health Economics 22 (3):505-518.

Gryparis, A., C. J. Paciorek, A. Zeka, J. Schwartz, and B. A. Coull. 2009. Measurement error caused by spatial misalignment in environmental epidemiology. Biostatistics 10 (2):258-274. 
Halliday, T. J. 2014. Unemployment and mortality: Evidence from the PSID. Social Science \& Medicine 113:15-22.

Harrell, F. E. 2015. Missing Data. In Regression Modeling Strategies: With Applications to Linear Models, Logistic and Ordinal Regression, and Survival Analysis, Springer Series in Statistics., ed. Jr. Harrell Frank E., 45-61. New York: Springer International Publishing https://doi.org/10.1007/978-3-319-19425-7_3 (last accessed 1 January 2020).

Hendryx, M. 2008. Mental Health Professional Shortage Areas in Rural Appalachia. The Journal of Rural Health 24 (2):179-182.

Institute for Health Metrics and Evaluation. 2016. United States Mortality Rates by County 1980-2014. http://ghdx.healthdata.org/record/ihme-data/united-states-mortality-rates-county1980-2014 (last accessed 29 December 2019).

Jia, H., D. G. Moriarty, and N. Kanarek. 2009. County-Level Social Environment Determinants of Health-Related Quality of Life Among US Adults: A Multilevel Analysis. Journal of Community Health 34 (5):430-439.

Kasl, S. V. 1979. Mortality and the business cycle: some questions about research strategies when utilizing macro-social and ecological data. American Journal of Public Health 69 (8):784-788.

Khana, D., L. M. Rossen, H. Hedegaard, and W. Margaret. 2018. A Bayesian spatial and temporal modeling approach to mapping geographic variation in mortality rates for subnational areas with R-INLA. Journal of Data Science 16 (1):147-182.

Laanani, M., W. Ghosn, E. Jougla, and G. Rey. 2015. Impact of unemployment variations on suicide mortality in Western European countries (2000-2010). Journal of Epidemiology and Community Health 69 (2):103-109.

van Lenthe, F. J., L. N. Borrell, G. Costa, A. V. Diez Roux, T. M. Kauppinen, C. Marinacci, P. Martikainen, E. Regidor, M. Stafford, and T. Valkonen. 2005. Neighbourhood unemployment and all cause mortality: a comparison of six countries. Journal of Epidemiology and Community Health 59 (3):231-237.

Lin, R.-T., D. C. Christiani, I. Kawachi, T.-C. Chan, P.-H. Chiang, and C.-C. Chan. 2016. Increased Risk of Respiratory Mortality Associated with the High-Tech Manufacturing Industry: A 26-Year Study. International Journal of Environmental Research and Public Health 13 (6):557.

Mäki, N., and P. Martikainen. 2012. A register-based study on excess suicide mortality among unemployed men and women during different levels of unemployment in Finland. Journal of Epidemiology and Community Health 66 (4):302-307.

Manson, S., J. Schroeder, D. Van Riper, and S. Ruggles. 2019. IPUMS National Historical Geographic Information System: Version 14.0. https://doi.org/10.18128/D050.V14.0 (last accessed 29 December 2019).

Martikainen, P. T., and T. Valkonen. 1996. Excess mortality of unemployed men and women during a period of rapidly increasing unemployment. The Lancet 348 (9032):909-912. 
McLeod, C. B., J. N. Lavis, Y. C. MacNab, and C. Hertzman. 2012. Unemployment and Mortality: A Comparative Study of Germany and the United States. American Journal of Public Health 102 (8):1542-1550.

Miller, D. L., M. E. Page, A. H. Stevens, and M. Filipski. 2009. Why Are Recessions Good for Your Health? American Economic Review 99 (2):122-127.

Milner, A., A. Page, and A. D. LaMontagne. 2013. Long-Term Unemployment and Suicide: A Systematic Review and Meta-Analysis. PLoS ONE 8 (1(e51333)).

https://www.ncbi.nlm.nih.gov/pmc/articles/PMC3547020/ (last accessed 26 January 2020).

Milner, A., A. Page, and A. D. LaMontagne. 2014. Cause and effect in studies on unemployment, mental health and suicide: a meta-analytic and conceptual review. Psychological Medicine 44 (5):909-917.

Moody, L. N., E. Satterwhite, and W. K. Bickel. 2017. Substance use in rural Central Appalachia: Current status and treatment considerations. Journal of Rural Mental Health 41 (2):123-135.

Moortel, D. D., P. Hagedoorn, C. Vanroelen, and S. Gadeyne. 2018. Employment status and mortality in the context of high and low regional unemployment levels in Belgium (20012011): A test of the social norm hypothesis across educational levels. PLOS ONE 13 (2):e0192526.

Moser, K. A., A. J. Fox, and D. R. Jones. 1984. Unemployment and Mortality in the OPCS Longitudinal Study. The Lancet 324 (8415):1324-1329.

Mueller, J. T., S. Y. Park, and A. J. Mowen. 2019. The relationship between parks and recreation per capita spending and mortality from 1980 to 2010: A fixed effects model. Preventive Medicine Reports 14:100827.

Mustard, C. A., A. Bielecky, J. Etches, R. Wilkins, M. Tjepkema, B. C. Amick, P. M. Smith, and K. J. Aronson. 2013. Mortality following unemployment in Canada, 1991-2001. BMC Public Health 13 (1):441.

Neumayer, E. 2004. Recessions lower (some) mortality rates: evidence from Germany. Social Science \& Medicine 58 (6):1037-1047.

Norström, T., and H. Grönqvist. 2015. The Great Recession, unemployment and suicide. Journal of Epidemiology and Community Health 69 (2):110-116.

Pierce, A. 1967. The Economic Cycle and the Social Suicide Rate. American Sociological Review 32 (3):457-462.

Pierce, J. R., and P. K. Schott. 2016. Trade Liberalization and Mortality: Evidence from U.S. Counties. National Bureau of Economic Research. http://www.nber.org/papers/w22849 (last accessed 4 January 2020).

Probst, C., M. Roerecke, S. Behrendt, and J. Rehm. 2014. Socioeconomic differences in alcohol-attributable mortality compared with all-cause mortality: a systematic review and metaanalysis. International Journal of Epidemiology 43 (4):1314-1327. 
Quick, H. 2019. Estimating County-Level Mortality Rates Using Highly Censored Data From CDC WONDER. Preventing Chronic Disease 16:180441.

R Core Team. 2019. R: A Language and Environment for Statistical Computing Version 3.6.1. Vienna, Austria: R Foundation for Statistical Computing. https://www.R-project.org/.

Roelfs, D. J., E. Shor, A. Blank, and J. E. Schwartz. 2015. Misery loves company? A metaregression examining aggregate unemployment rates and the unemployment-mortality association. Annals of Epidemiology 25 (5):312-322.

Roelfs, D. J., E. Shor, K. W. Davidson, and J. E. Schwartz. 2011. Losing life and livelihood: A systematic review and meta-analysis of unemployment and all-cause mortality. Social Science \& Medicine 72 (6):840-854.

Rue, H., S. Martino, and N. Chopin. 2009. Approximate Bayesian inference for latent Gaussian models by using integrated nested Laplace approximations. Journal of the Royal Statistical Society: Series B (Statistical Methodology) 71 (2):319-392.

Ruggles, S. 2014. Big Microdata for Population Research. Demography 51 (1):287-297.

Ruhm, C. J. 2000. Are Recessions Good for Your Health? The Quarterly Journal of Economics 115 (2):617-650.

Shamblin, S. R., N. F. Williams, and J. R. Bellaw. 2012. Conceptualizing homelessness in rural Appalachia: Understanding contextual factors relevant to community mental health practice. Journal of Rural Mental Health 36 (2):3-9.

Singh, G. K., M. Siahpush, and S. F. Altekruse. 2013. Time Trends in Liver Cancer Mortality, Incidence, and Risk Factors by Unemployment Level and Race/Ethnicity, United States, 1969-2011. Journal of Community Health 38 (5):926-940.

Spiegelhalter, D. J., N. G. Best, B. P. Carlin, and A. V. D. Linde. 2002. Bayesian measures of model complexity and fit. Journal of the Royal Statistical Society: Series B (Statistical Methodology) 64 (4):583-639.

Tapia Granados, J. A., J. S. House, E. L. Ionides, S. Burgard, and R. S. Schoeni. 2014. Individual Joblessness, Contextual Unemployment, and Mortality Risk. American Journal of Epidemiology 180 (3):280-287.

The Bureau of Labor Statistics. 2020. Consumer Price Index Inflation Calculator. https://www.bls.gov/data/inflation_calculator.htm (last accessed 5 January 2020).

The National Bureau of Economic Research. 2020. US Business Cycle Expansions and Contractions. https://www.nber.org/cycles.html (last accessed 3 January 2020).

United States Census Bureau. 2015. TIGER/Line Shapefiles. https:/www.census.gov/geographies/mapping-files/time-series/geo/tiger-line-file.2014.html (last accessed 29 December 2019).

U.S. Bureau of Labor Statistics. 2019. Local Area Unemployment Statistics. https://www.bls.gov/lau/data.htm (last accessed 29 December 2019). 
Verbosio, F., A. De Coninck, D. Kourounis, and O. Schenk. 2017. Enhancing the scalability of selected inversion factorization algorithms in genomic prediction. Journal of Computational Science 22:99-108.

Voss, M., L. Nylén, B. Floderus, F. Diderichsen, and P. D. Terry. 2004. Unemployment and Early Cause-Specific Mortality: A Study Based on the Swedish Twin Registry. American Journal of Public Health 94 (12):2155-2161.

Waitzman, N. J., and K. R. Smith. 1998. Phantom of the area: poverty-area residence and mortality in the United States. American Journal of Public Health 88 (6):973-976.

Watanabe, S. 2009. Algebraic geometry and statistical learning theory. New York: Cambridge University Press.

Watson, P., and S. Deller. 2017. Economic diversity, unemployment and the Great Recession. The Quarterly Review of Economics and Finance 64:1-11.

Zheng, H. 2012. Do people die from income inequality of a decade ago? Social Science \& Medicine 75 (1):36-45. 


\section{Supplementary material 1}

Let there be spatial entities comprise nine square areas as below, with the temporal dependence of the first-order random walk and let the total length of the time series be three.

\begin{tabular}{|c|c|c|}
\hline 1 & 2 & 3 \\
\hline 4 & 5 & 6 \\
\hline 7 & 8 & 9 \\
\hline
\end{tabular}

In this case, area 1 is assumed to be adjacent to areas 2, 4 and 5, area 2 is adjacent to areas 1 , 3, 4, 5 and 6, and so on. Each structure can be expressed in matrices, say, $\mathbf{W}$ and $\mathbf{T}$ :

$$
\begin{aligned}
& \mathbf{W}=\left(\begin{array}{ccccccccc}
1 & 1 & 0 & 1 & 0 & 0 & 0 & 0 & 0 \\
1 & 1 & 1 & 0 & 1 & 0 & 0 & 0 & 0 \\
0 & 1 & 1 & 0 & 0 & 1 & 0 & 0 & 0 \\
1 & 0 & 0 & 1 & 1 & 0 & 1 & 0 & 0 \\
0 & 1 & 0 & 1 & 1 & 1 & 0 & 1 & 0 \\
0 & 0 & 1 & 0 & 1 & 1 & 0 & 0 & 1 \\
0 & 0 & 0 & 1 & 0 & 0 & 1 & 1 & 0 \\
0 & 0 & 0 & 0 & 1 & 0 & 1 & 1 & 1 \\
0 & 0 & 0 & 0 & 0 & 1 & 0 & 1 & 1
\end{array}\right) \\
& \mathbf{T}=\left(\begin{array}{ccc}
1 & -1 & 0 \\
-1 & 2 & -1 \\
0 & -1 & 1
\end{array}\right)
\end{aligned}
$$

Matrices $\mathbf{W}$ and $\mathbf{T}$ are sparse as seen above. By the definition of Kronecker product, their interaction term is

$$
\mathbf{W} \otimes \mathbf{T}=\left(\begin{array}{cccccccccc}
1 & -1 & 0 & 1 & -1 & 0 & \cdots & 0 & 0 & 0 \\
-1 & 2 & -1 & -1 & 2 & -1 & \cdots & 0 & 0 & 0 \\
0 & -1 & 1 & 0 & -1 & 1 & \cdots & 0 & 0 & 0 \\
1 & -1 & 0 & 1 & -1 & 0 & \cdots & 0 & 0 & 0 \\
-1 & 2 & -1 & -1 & 2 & -1 & \cdots & 0 & 0 & 0 \\
0 & -1 & 1 & 0 & -1 & 1 & \cdots & 0 & 0 & 0 \\
\vdots & \vdots & \vdots & \vdots & \vdots & \vdots & \ddots & \vdots & \vdots & \vdots \\
0 & 0 & 0 & 0 & 0 & 0 & \cdots & 1 & -1 & 0 \\
0 & 0 & 0 & 0 & 0 & 0 & \cdots & -1 & 2 & -1 \\
0 & 0 & 0 & 0 & 0 & 0 & \cdots & 0 & -1 & 1
\end{array}\right)
$$

The result should have $9 \times 3 \times 9 \times 3=27 \times 27$ elements. To note, when the spatial or temporal structure was imposed as identically independently distributed (i.i.d.), $\mathbf{T}$ equals to an identity matrix. 


\section{Supplementary material 2}

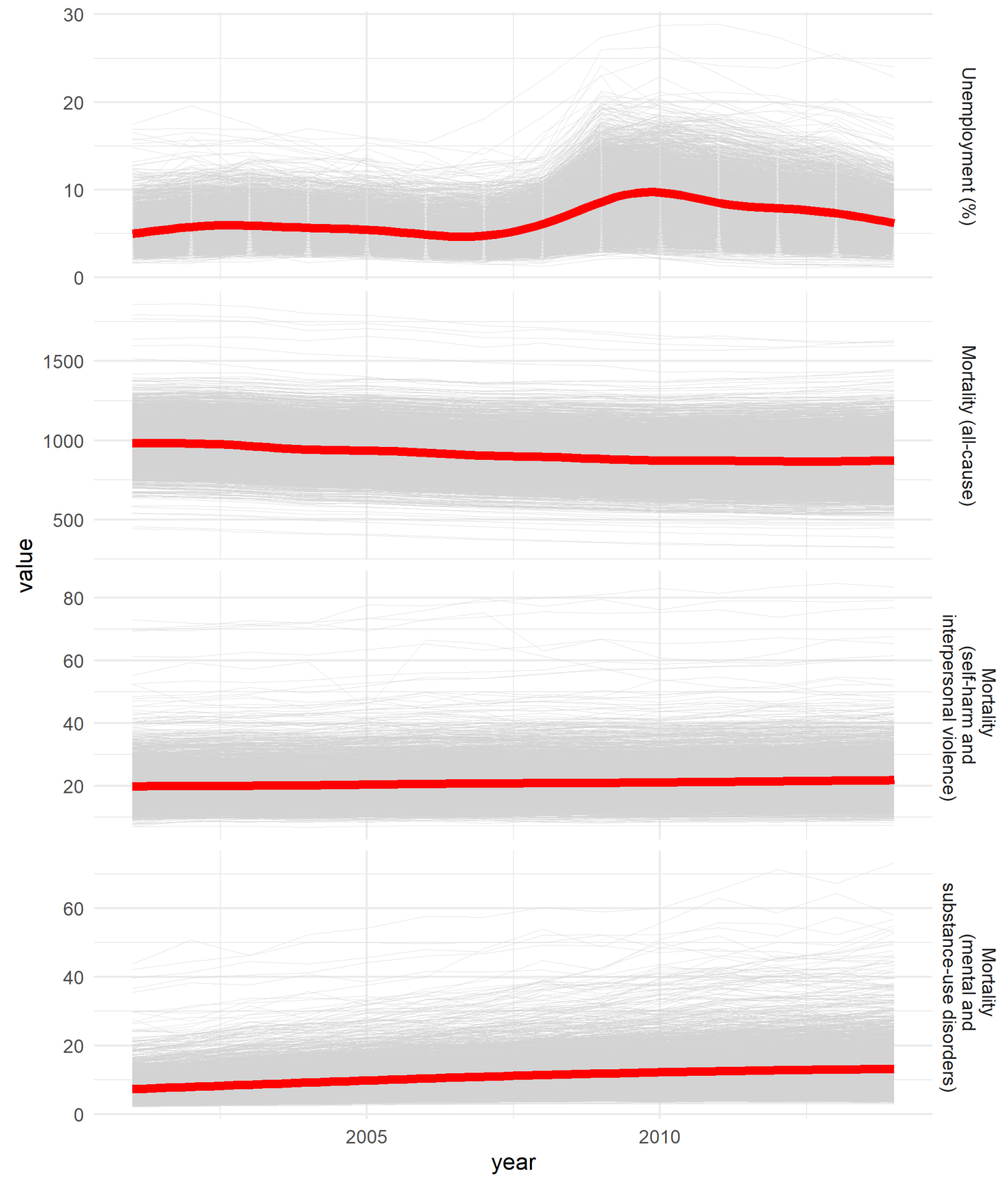

Figure S1. Temporal trends of unemployment rates and mortality rates for 3,108 coterminous US counties (grey lines) and the overall trends (red lines; connected medians of counties per year) (Note: the unit of mortality rates is count per 100,000 population). 

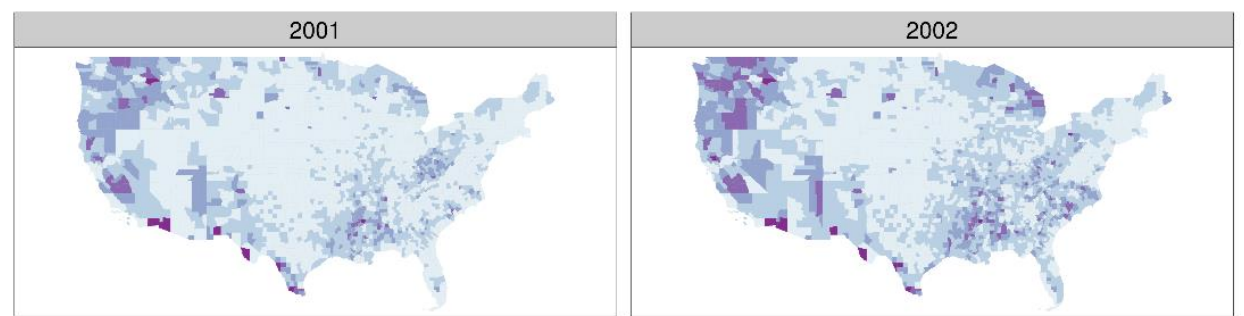

UELAG1
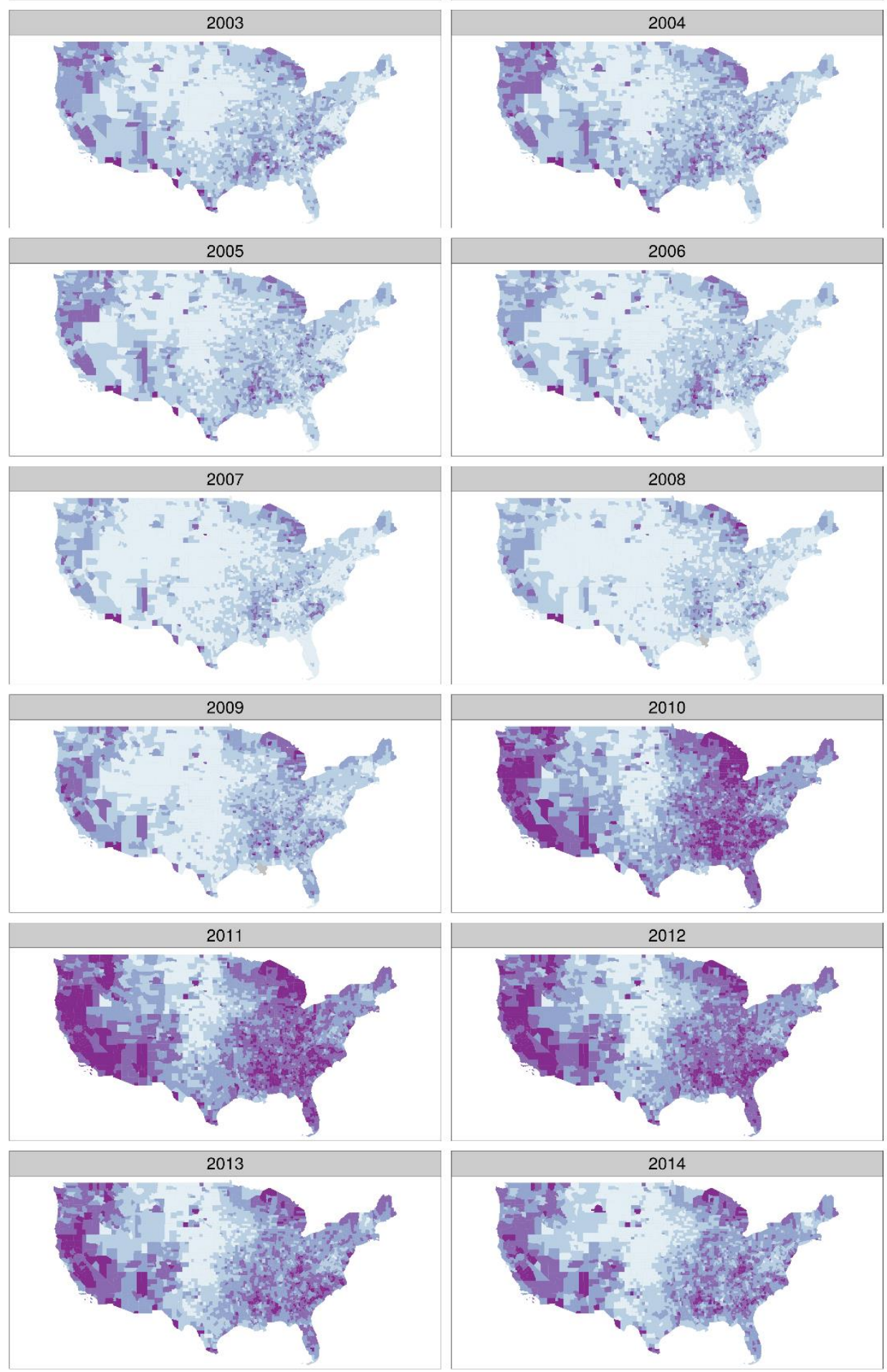

1.10 to 4.65

4.65 to 6.65

6.65 to 9.05

9.05 to 12.45

12.45 to 28.90

Missing

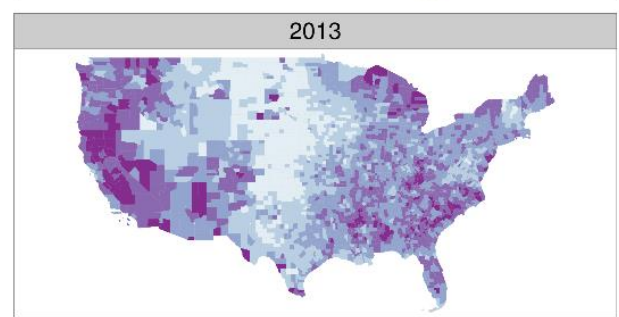

Figure S2. Spatiotemporal change of one-year lagged unemployment rates in 3,108 coterminous US counties in 2001-2014. 


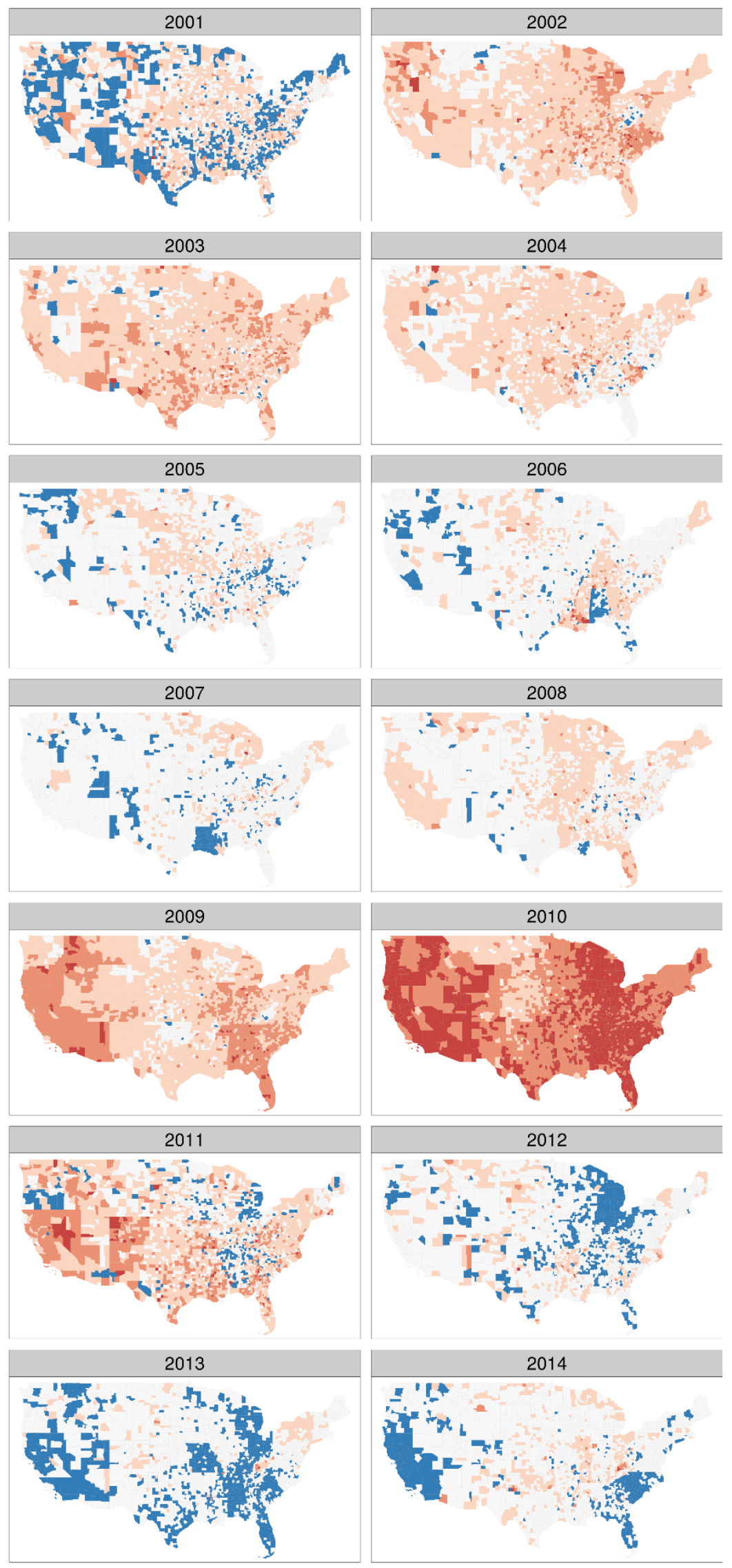

Unemployment rate (change in \%p)

-13.90 to -1.15

-1.15 to 0.05

0.05 to 1.25

1.25 to 3.25

3.25 to 13.60 

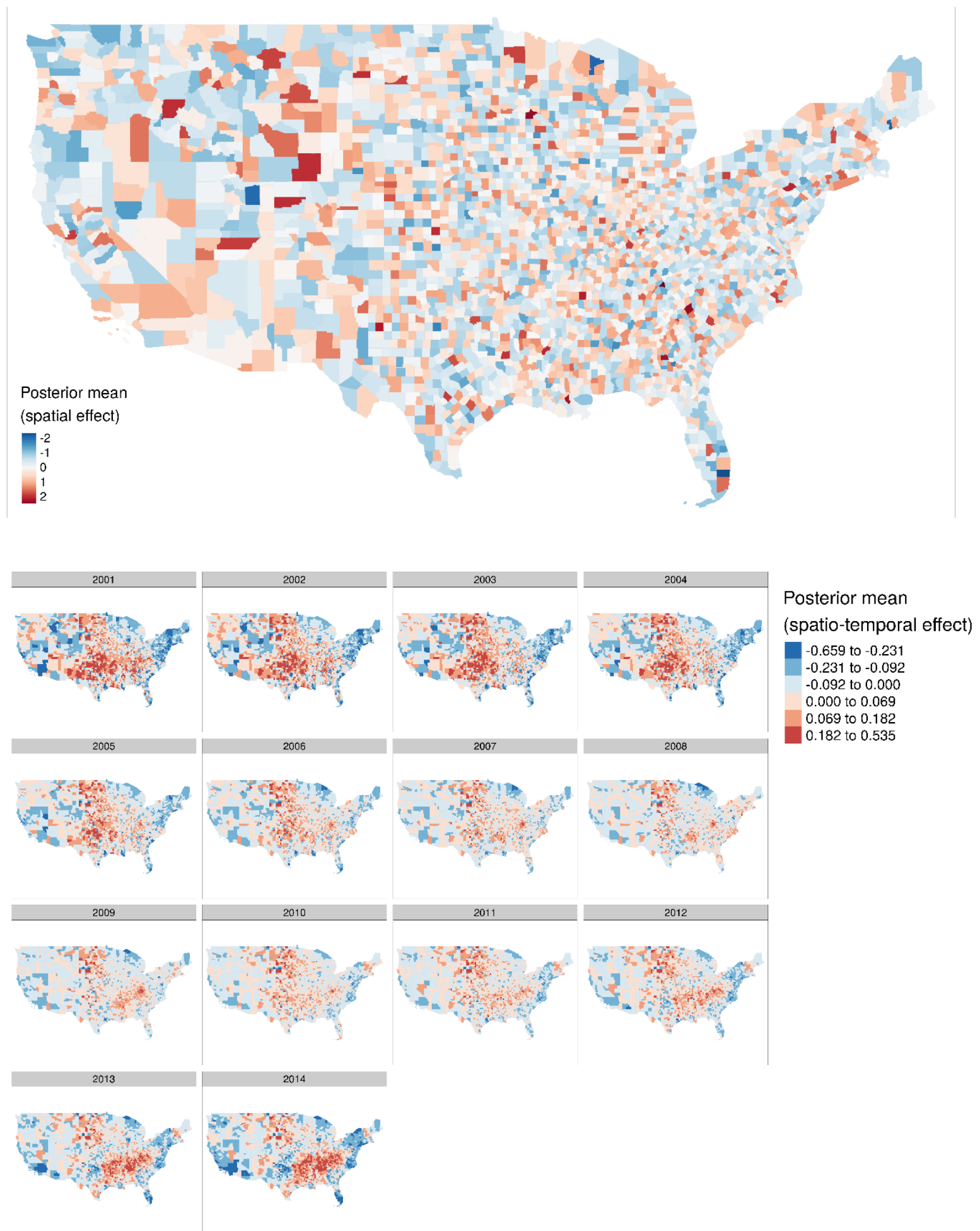

Figure S4. Spatial effect (above) and spatiotemporal interaction (below) in the all-cause mortality model 3-2 (Note: the legend was generated by using Fisher's classification scheme). 

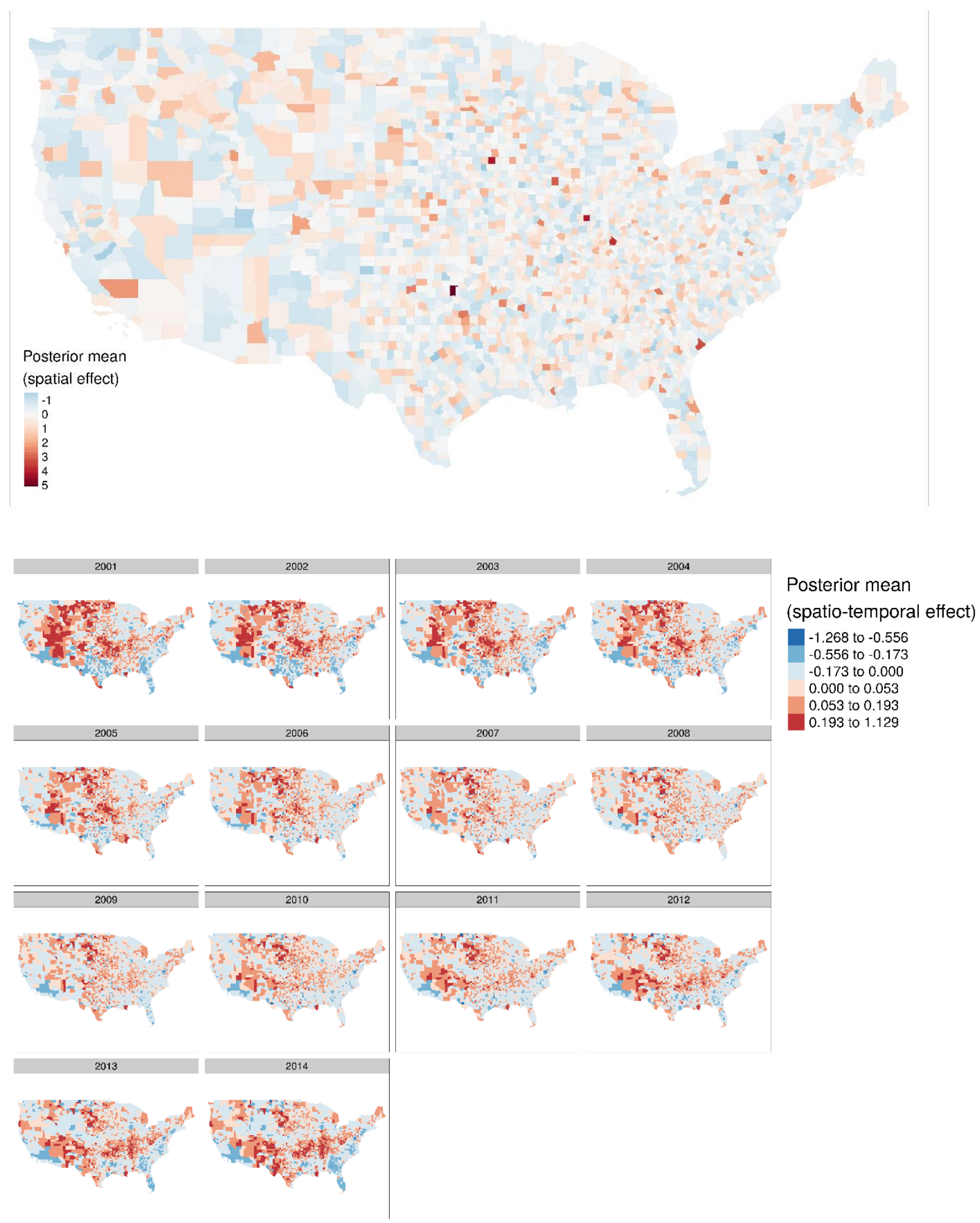

Figure S5. Spatial effect (above) and spatiotemporal interaction (below) in the self-harm and interpersonal violence mortality model (Note: the legend was generated by using Fisher's classification scheme). 

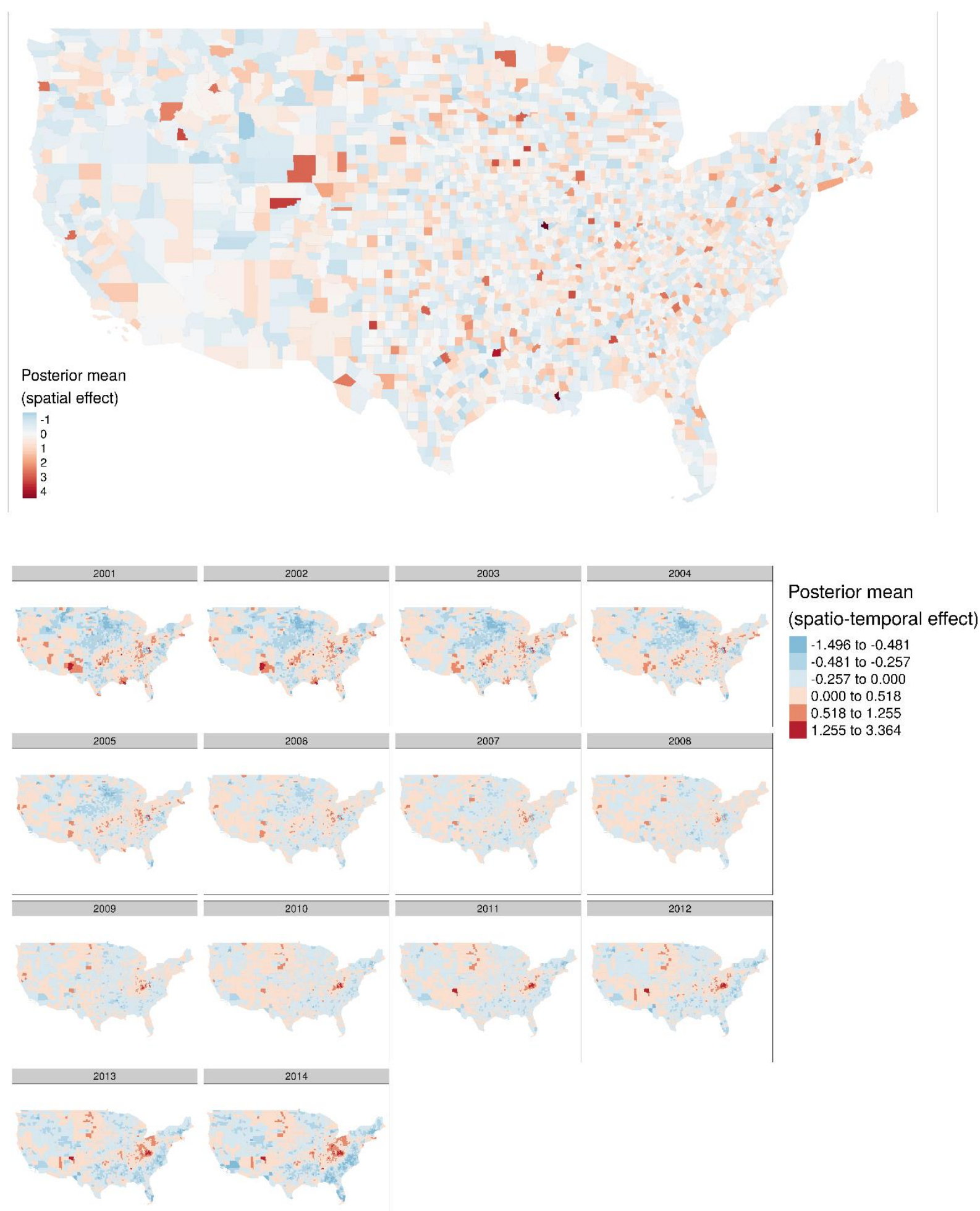

Figure S6. Spatial effect (above) and spatiotemporal interaction (below) in the mental disorder and substance-use disorders mortality model (Note: the legend was generated by using Fisher's classification scheme). 


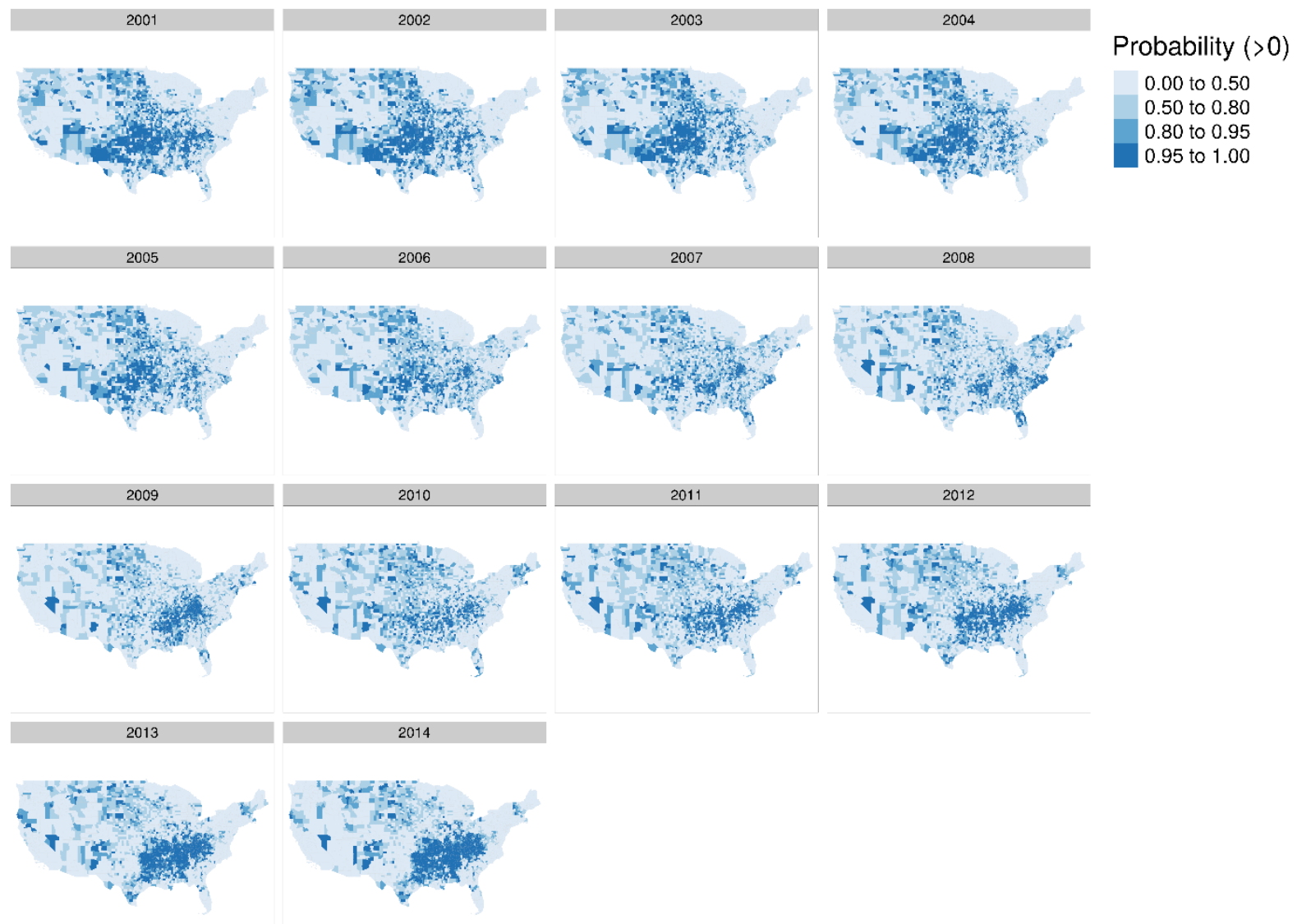

Figure S7. Probability map of the spatiotemporal unemployment rates' effect in the all-cause mortality model (Note: the map displays the probability of $b_{i t 1,1}>0$ ). 


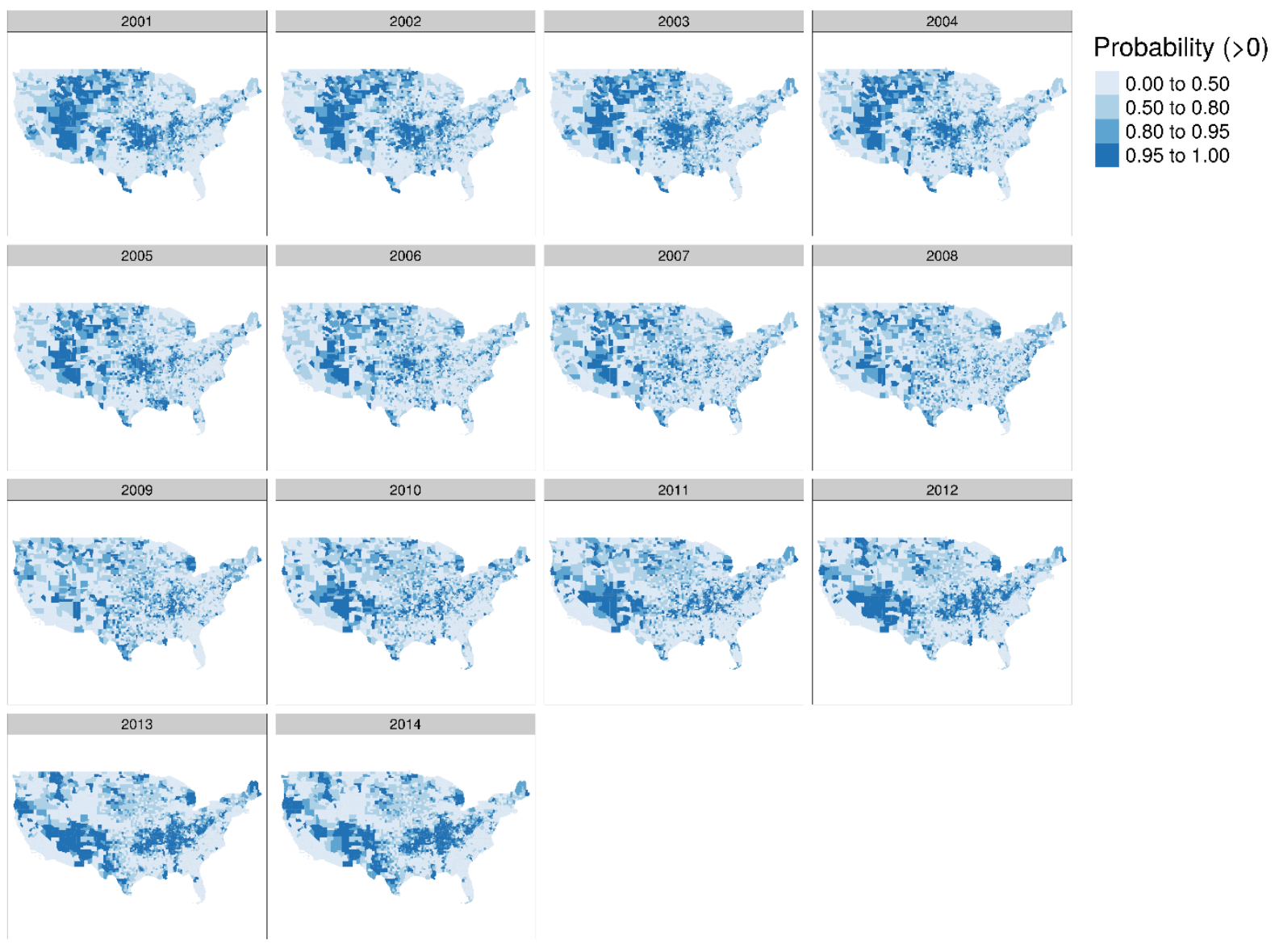

Figure S8. Probability map of the spatiotemporal unemployment rates' effect in the self-harm and interpersonal violence mortality model (Note: the map displays the probability of $b_{i t 1,1}>$ $0)$. 


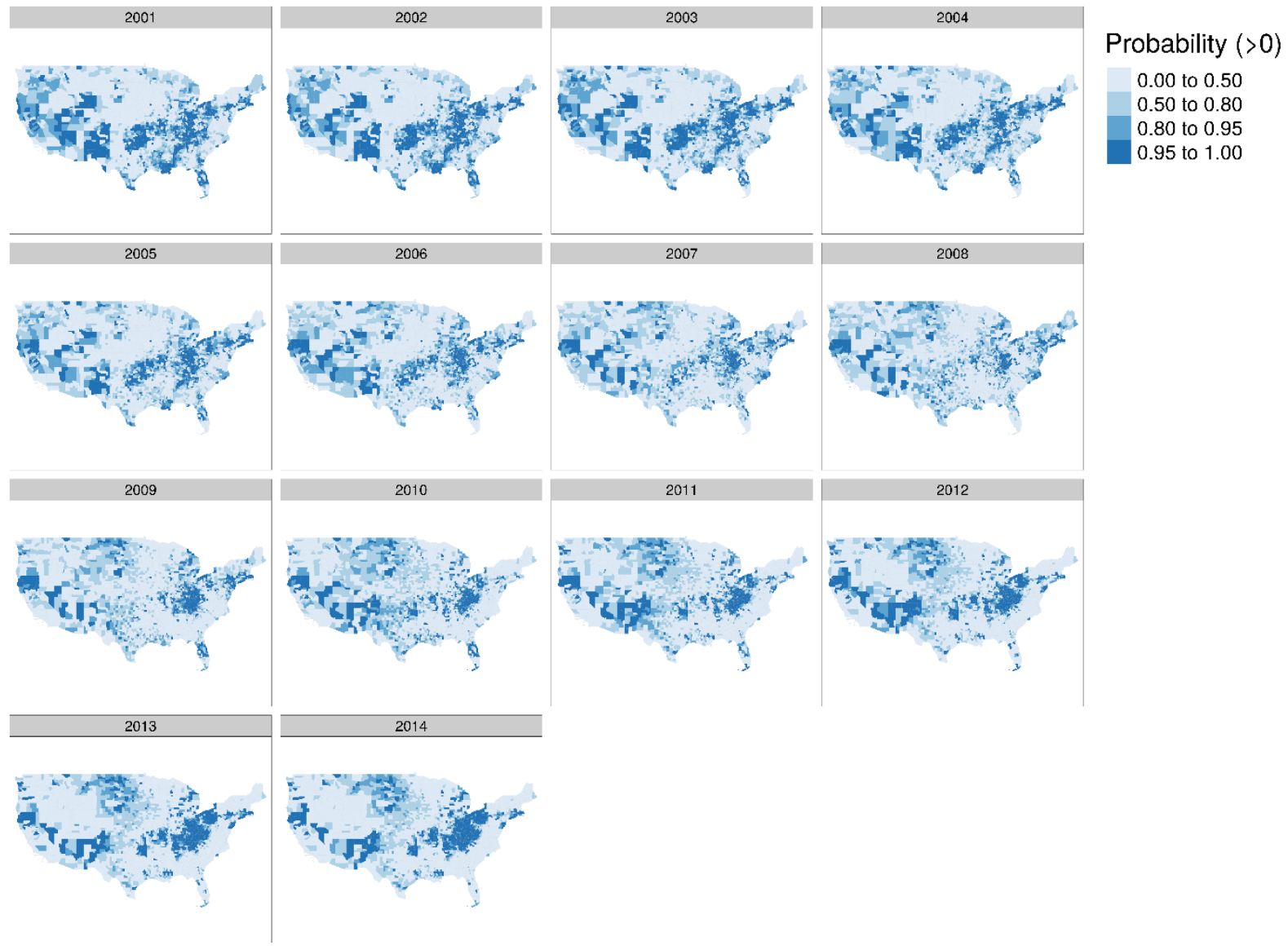

Figure S9. Probability map of the spatiotemporal unemployment rates' effect in the mental and substance-use mortality model (Note: the map displays the probability of $b_{i t 1,1}>0$ ). 


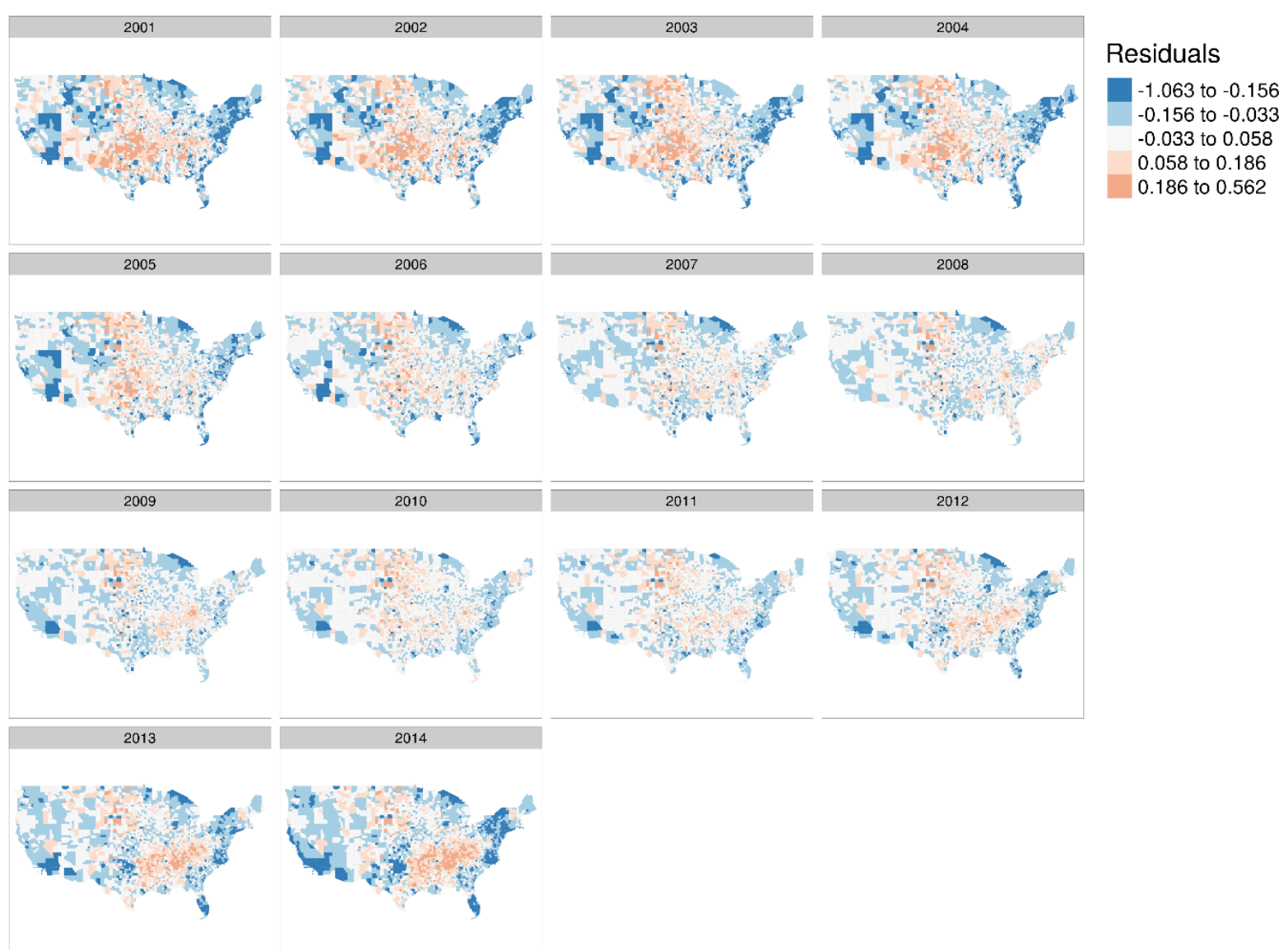

Figure S10. Residual maps of the all-cause mortality model 3-2. 


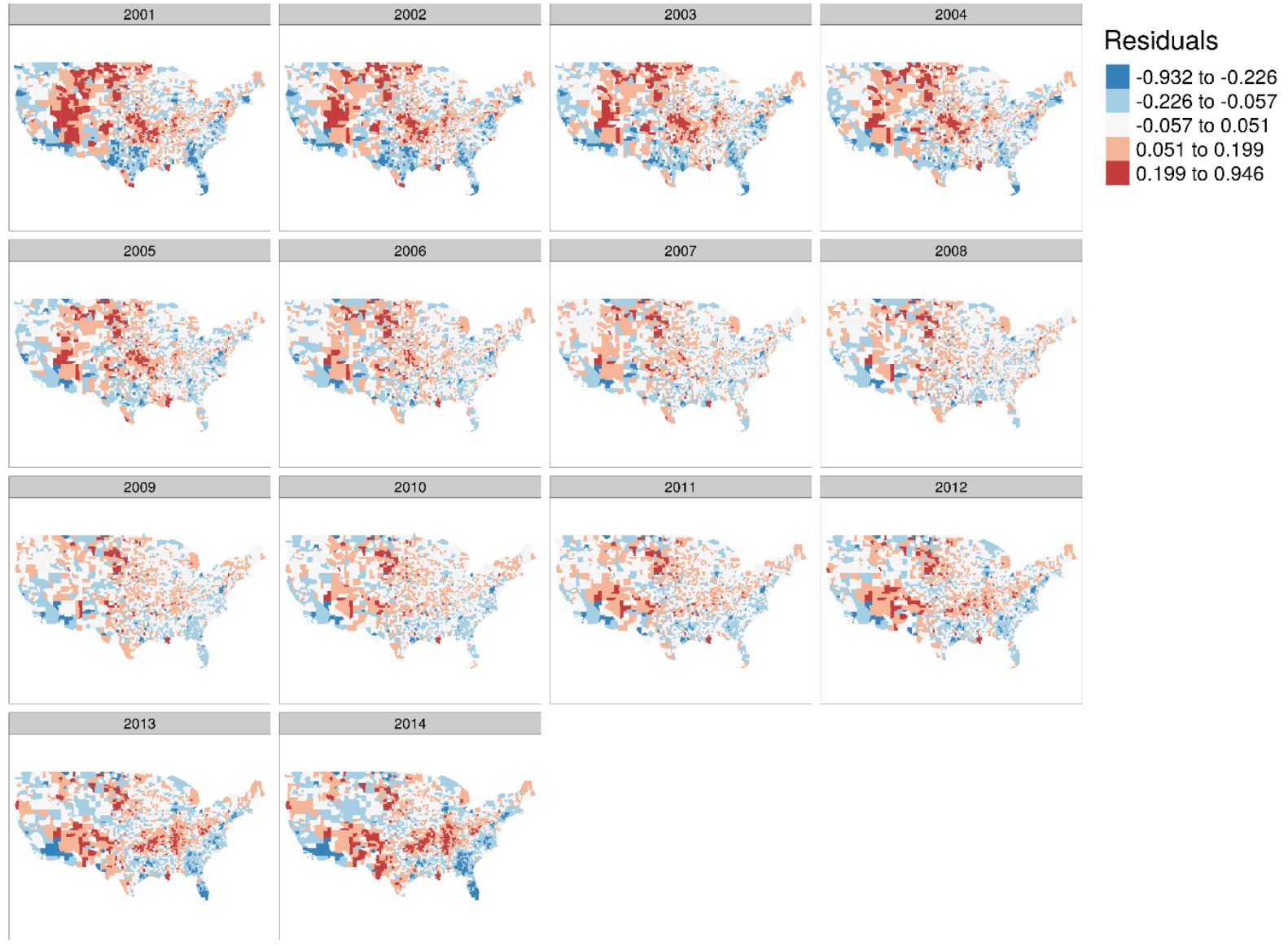

Figure S11. Residual maps of the self-harm and interpersonal violence mortality model 3-2. 


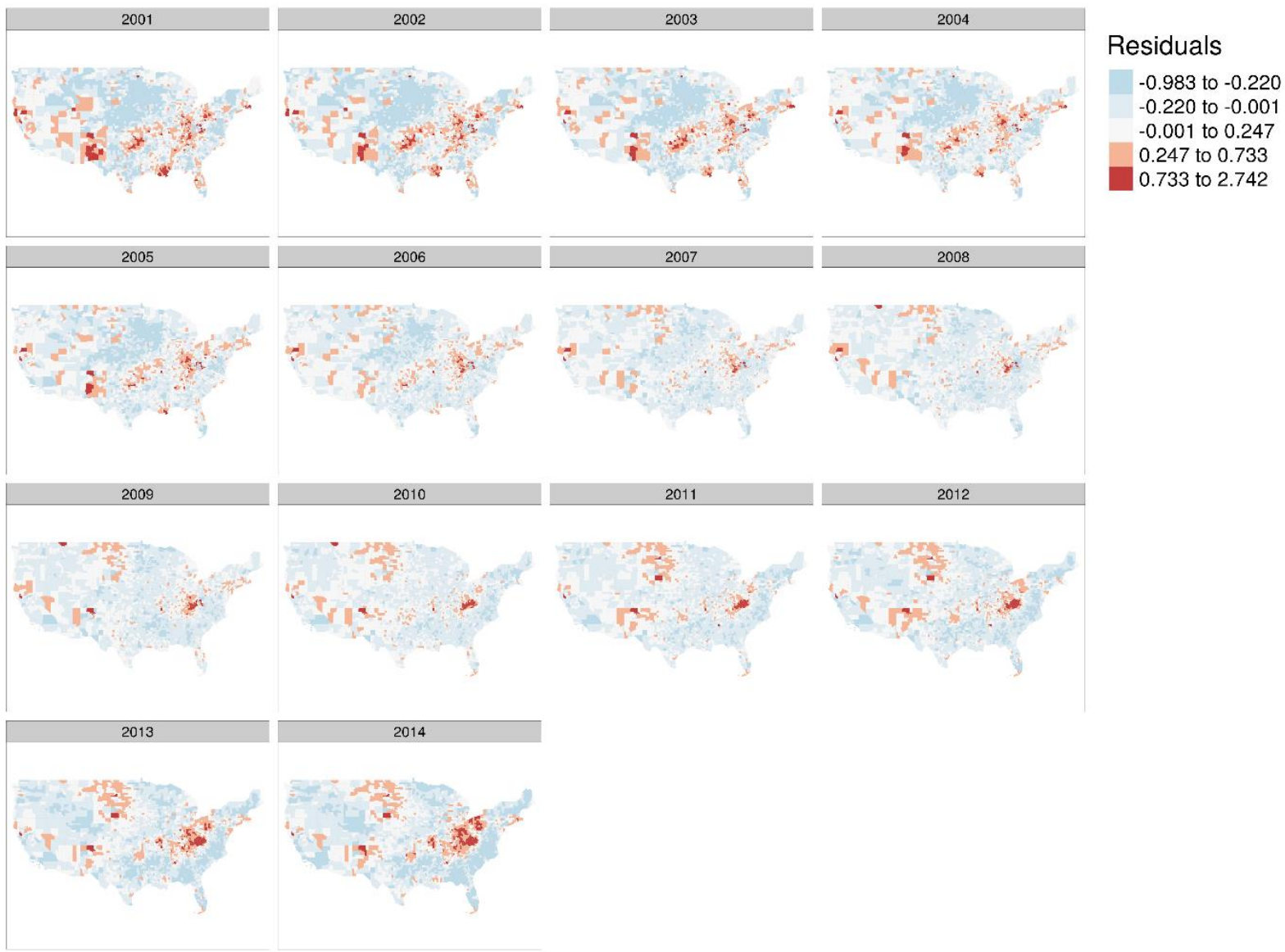

Figure S12. Residual maps of the mental and substance-use disorder mortality model 3-2. 